\title{
INTRODUCTION
}

Campus Talk is a research-based guide for upper-intermediate/advanced adult learners of English (Common European Framework of Reference (CEFR) B1-C2) to promote interactional language awareness and develop active listening skills and strategies. It aims at enhancing learners' appropriate English language use, and facilitating their everyday social communication in both academic and non-academic environments on campus.

The two-volume Campus Talk textbook can be used as a self-reference guide and practice resource by individual learners or as an English as a Second/Foreign Language (ESL/EFL) textbook in the classroom. It is designed to meet the English language development needs of a wide range of learners, including but not limited to:

- international students who intend to complete undergraduate and/or graduate studies in an English-speaking country

- international teaching assistants (ITAs)

- exchange and post-doctoral students, as well as visiting scholars who study, work, and/or conduct research in an English-speaking country

- learners who need to take Test of English for International Communication (TOEIC) or G1 Advanced (CAE) tests.

Through a learner need-based syllabus, Campus Talk:

- ensures that the learners are exposed to the most salient and widely used lexico-grammatical patterns of spoken English discourse, in and outside academia, that are pertinent to their level

- provides plenty of opportunities to practice and assess interactive listening skills and strategies

- facilitates conversation management by providing knowledge of and practice in conversation maintenance strategies in a variety of situations

- promotes practice of common speech act routines with a focus on interaction rather than on speaker turns 
- encourages learners' observation skills and noticing through language corpus investigation and analysis of everyday situational language use

- enhances awareness of a wide range of communication strategies that learners can use to interact fluently, confidently, and effectively

- draws learners' attention to socio-cultural aspects of communication in English and how they affect interaction

- promotes learners' self-reflection and independent management of their learning through learner error analysis and self-assessment tools.

Campus Talk is comprised of two volumes. Each volume contains four instructional units and each unit consists of three topic-/skill-related parts or mini-units.

The unit introduction highlights the unit goals and concrete learner benefits. Each unit includes interactional tasks and activities which provide plenty of opportunities for observation and practice. There is a set of self-study exercises in each unit, too. The unit tasks and activities culminate in the unit main speaking task and a unit quiz. Each unit has a self-assessment section at the end of the unit, which invites the learners to track and reflect upon their unit benefits and progress made. The usage-informed vocabulary list, also located at the end of each unit, is intended for use by the learner for self-study and classroom practice.

The learning goals for each unit of Campus Talk Volume 2 are as follows:

\section{Unit 5}

In this unit, students learn to:

- share a conversational story using appropriate strategies (such as pre-announcers, reference, and so on)

- deliver a conversational story with attention to stress, pauses, and intonation

- engage in a conversational story by demonstrating appropriate listenership (such as ask questions, show surprise, and make an evaluation).

\section{Unit 6}

In this unit, students learn to:

- make a pre-complaint and complaint with sensitivity to tone

- respond to a complaint by using various conversational strategies

- make and respond to an apology with attention to culture-specific situations and relevant strategies. 


\section{Unit 7}

In this unit, students learn to:

- build rapport with their audience in a presentation by drawing attention, setting expectations, and maintaining visual contact

- keep their audience focused by emphasizing intention, expressing stance, and previewing/reviewing the main points

- manage interaction with their audience in a Q\&A session, and give and respond to feedback.

\section{Unit 8}

In this unit, students learn to:

- make and accept/decline a pre-invitation and invitation

- give and respond to a compliment, depending on its purpose and audience

- understand and respond to humor with attention to topic and situation.

Each Unit contains a number of listening activities. The MP3 files for the listening activities can be accessed on the student's companion website, which complements this book. In the book, an icon appears in the text to show where there is a listening file available.

Several units contain a language corpus investigation activity. The corpora used are the Corpus of Contemporary American English (COCA; available at <https://www. english-corpora.org/coca/> (last accessed October 22, 2020)), and the Michigan Corpus of Academic Spoken English (MICASE; available at <https://quod.lib.umich.edu/ cgi/c/corpus/corpus $>$, (last accessed October 22, 2020)), and for each activity there is also an online screencast to help demonstrate the procedures for doing the activity. An icon appears in the text for the activity to indicate that there is a screencast. These screencasts can be found on the student's companion website.

Campus Talk student's companion website (https://campustalk.online/) also offers an online workbook for students, with supplementary activities and language practice resources.

In addition, a Teacher's Notes booklet is downloadable via the Edinburgh University Press website (edinburghuniversitypress.com/campustalk2). This booklet contains guidance on the purpose of each activity in Campus Talk and suggests ways to structure the activity in class. 


\section{EXPLANATION OF ICONS USED IN THE BOOKS}

MP3 file for listening activity is available on the Edinburgh University Press website (edinburghuniversitypress.com/campustalk2).

Screencast for corpus investigation activity is available on the Edinburgh University Press website (edinburghuniversitypress.com/campustalk2). 